\title{
Chapter 11 \\ Employee Representatives in Spain. Which are the Perceptions and Expectations by Employers?
}

\author{
Lourdes Munduate, Ana Belén García, Erica Pender, Patricia Elgoibar \\ and Francisco José Medina
}

The current Spanish industrial relations climate is very specific in comparison to the rest of Europe. First, Spain is one of the European countries that has been most affected by the financial and economic crises (Aiginger 2013; Sanz de Miguel 2013). Second, Spain has a particularly competitive industrial relations climate with a strong tradition of class unions and a centralized collective bargaining system, in addition to an important legal coverage of the union actions (Banyuls et al. 2009; Benito 2012). Thirdly, the financial crisis and the external debt have led to the imposition of austerity measures from the EU, which have put both the government and the social partners under strong pressure. Thus, Spain has experimented a period of unprecedented reforms, particularly from the beginning of 2010 onwards (Fishman 2012). Fourthly, the changes in regulations in the labor market, employment policies and the structure of the collective bargaining - embedded in a context of constant socio-economical decay-have influenced the role of the social agents, levelling the way towards a decentralized system and a renovation of the institutional framework. These changes and the challenges they involve have placed ERs as key parts at the organizational level, with an important role in social innovation and the competitiveness of the organization. We analyze the role of ERs in the current

L. Munduate $(\bowtie) \cdot$ F. J. Medina

University of Seville, Seville, Spain

e-mail: munduate@us.es

A. B. García · E. Pender

KU Leuven, Belgium \& University of Seville, Seville, Spain

e-mail: AnaBelen.GarciaJurado@kuleuven.be

P. Elgoibar

IESEG School of Management, Paris, France

e-mail: p.elgoibar@ieseg.fr

E. Pender

e-mail: erica.romeropender@kuleuven.be

F. J. Medina

e-mail: fjmedina@us.es

(C) The Author(s) 2015

M. Euwema et al. (eds.), Promoting Social Dialogue in European Organizations,

Industrial Relations \& Conflict Management 1, DOI 10.1007/978-3-319-08605-7_11 
context in which labor relations are embedded in Spain. How is this role perceived by management and what do they expect from ERs in this new context?

This chapter will start by describing labor relations in Spain, since the legal and historical framework are key for understanding the role of ERs in the different European industrial relations systems (Elgoibar 2013; Hyman 2005). The results of the study as well as the strategies for the improvement of social dialogue proposed and promoted by the European Commission (2010) are covered in the present study.

\subsection{The Context: Industrial Relations in Spain}

The changes carried out in labor market and economy policies haven't resulted in an employment growth as expected, instead cohesion has become strongly threatened, and most of the socioeconomic imbalances still remain. The costs of the crisis include the loss of wealth, but also of rights and guarantees for citizens, as well as an increase of poverty, risks of social exclusion, inequality and deterioration of social integration (Molina and Miguelez 2013; Unceta et al. 2014). The effects of the crisis - initiated in 2008 - highlight its complexity, severity, permanence and persistence throughout the last years (Ramos and Peiró 2014). According to the high unemployment rate, authors such as Fishman (2012) state that the changes implemented have suffered from an inability to identify and act on the country's genuine structural shortfalls and instead have repeatedly attempted to address chronically high unemployment through labor market deregulation. Other authors (CarballoCruz; Laborda 2010), explain that the increase of labor costs in the pre-crisis period reduced the Spanish competitiveness. Therefore, with the arrival of the crisis the organizations have been forced to reduce costs in order to maintain their market and this has been done by a reduction of the workforce. It has been related to the structural characteristics of the Spanish labor market, with low flexibility in wages and hours, which implies that reducing relative costs is only possible by adjusting or reducing workforce. At the same time, it's important to consider that the crisis has greatly affected an economy based on intensive personal services, but not on knowledge-intensive business services (construction, hotel industry and tourism, service to people), a very divided labor market (between the insiders or protected workers and the outsiders or workers who are at the borders of this classic model, unemployed or with precarious jobs), low productivity and the persistence of the housing bubble which shows itself as untenable (Ramos and Peiró 2014).

Therefore, understanding the national system, its characteristics and limits becomes essential to explore how to improve the social dialogue and the role of the social partners involved in the process. We will take a brief look at the sociopolitical and socioeconomic traditions that have shaped the employment relations' ideology in Spain (Martínez-Lucio and Weston 2007) and that are helpful when interpreting the development of social dialogue in austerity times. 


\subsubsection{The Historical Background of Spanish Industrial Relations}

The dictatorial regime in Spain (1939-1977) prohibited the freedom of association and the right to carry out industrial actions in organizations (Munduate 1993; Munduate et al. 1994). During the Franco era, production was mainly oriented to domestic markets with low wages and a majority of low skilled workers (Banyuls et al. 2009). The model combined economic growth with poor labor and social conditions, and high inequalities in terms of class and gender, as well as low trust between employers and employees (Miguélez and Prieto 2009).

The Spanish transition towards democracy at a time of deep industrial restructuring (1975-1982) settled powerful reforms (Sánchez-Cuenca and Aguilar 2009), regarding economic measures (social pacts as the "Moncloa Agreements" in early 1980s), freedom of association (the agreement of the Union Freedom in 1978) and workers' rights (Spanish Workers' Statute in 1979). Social dialogue played a key role as a socioeconomic governance mechanism during the country's return to democracy. The Spanish Workers' Statute established the workers' rights and promoted a centralized collective bargaining model. It was a counterweight to the long period of no union protection of workers. Therefore, ERs' recognition in Spain is one of the youngest in Western Europe and the tradition of adversarial and confrontational relations generated during the Franco era still persists (Elgoibar et al. 2012; Martinez-Lucio 2008; Rocha 2010). With the support on the legal framework and the centralized model of labor relations, the union transferred action to the institutional action in business and consequently also to the collective bargaining. The period of social pacts in the early 1980s was followed by increasing conflict between the socialist government (elected in 1982) and the TUs, due to a liberal politic promoted by the government.

During the crisis of the early 1990s, the lack of consensus between the government and the social partners brought a unilateral regulation of the labor market and collective bargaining. The government refused to support a centralized wage settlement. Between 1986 and 1994, the discontent of workers with this economic policy was expressed through three general strikes (Rigby and Lawlor 1994). The neo-liberal climate - characterized by temporary contracts and low salaries — created a new group of workers called "working poor" (Ruiz-Galvez Juzgado 2012). Working poor rates in Spain have been among the highest in Europe since then (Duran and Isusi 2010). Low salaries and unemployment continue to characterize the Spanish industrial relations system nowadays (Eurostat 2013).

Throughout the 1990s the first lines of flexibility were drawn. Nevertheless, collective labor agreements still had a tendency to be rigid and centralized. The flexibility established the possibility to even break away the wage of a company from the sector agreement, although only under authorization from the sectorial bargaining committee.

With the first signs of overcoming the crisis (1995), social dialogue was resumed and the ongoing period of growth was characterized as very prosperous in terms of 
social pacts. More than 20 national agreements were signed between social partners with overall indications for the development of collective bargaining with moderate wage increases that have prevailed over time. During these years and until the beginning of the current crisis (2008), Spain was able to improve the employment rate. However, it has remained below the European average (Ruiz-Galvez Juzgado 2012). The main sectors that contributed to the improvement were construction and real estate, as well as the tourism sector. Therefore, the bursting of the housing market bubble has been one of the main causes of the dramatic unemployment rate increase in the early stages of the crisis (Duran and Isusi 2010). However, other factors have contributed to the spread of unemployment to most sectors of the economy in a second stage of the crisis. A relevant factor had to do with the financial character of the economic crisis and the difficulty organizations were having in accessing credit. At the same time, the banking sector vulnerability was related to its policy of providing easy access to finance private consumption during the growth years (Molina and Miguelez 2013).

An important aspect of the Spanish socioeconomic context during the time of economic boom (1998-2007) has been its inability to cope with reforms related to the structural weaknesses of the Spanish economy. Together with the other southern European economies, Spain shows a low and stagnant productivity that is related to structural production weaknesses (Mas et al. 2012). In this way, social dialogue, which had served as an essential modernization tool during the transition and first years of democracy and as the basis of labor relations in Spain, now found itself having to confront the crisis with a difficult socioeconomic context.

\subsubsection{Social Dialogue Over the Period of Financial Crisis (2008-2013)}

One of the main defining features of the effects of the international financial crisis on the Spanish economy has been the continuous growth of the unemployment rate (26,03\% in 2013), and a dramatic youth unemployment of over $55 \%$ (Statistic National Institute 2013). Under these circumstances, many observers have tended to blame the Spanish collective bargaining system, characterized by a relatively high degree of centralization and coordination, accusing it of being too rigid and impeding companies from modifying working arrangements in order to adjust to the new demands (Sanz de Miguel 2013). This rigidity implies that reducing relative costs entails reducing workforce (Laborda 2010), due to a marked division between the insiders and the outsiders of the labor market. However, as mentioned earlier, the collective bargaining system and labor market management have not been the only responsible for the increase of unemployment. Other aspects of the crisis have also influenced this, for example the loss of capital and inversion decrease, the credit crisis (lack of liquid funds for credits) and the fiscal crisis (based on non-sustainable incomes produced mainly by the housing bubble) (Pérez García 2011; 2012). It is also true that the social agents have not been able to find a way of promoting 
innovative social dialogue that would pave the way out of the difficult situation that the country is going through. The inflexibility of the system has possibly acted as a "red line" in the chance of achieving constructive agreements that could help in the process, furthermore controlling the unemployment rate.

Although during the first stage of the crisis social agents were engaged in developing measures for making collective agreements and labor market institutions more flexible, the results were not productive. Both collective agreements - the one carried out in 2010 and the one from 2011 - were unilaterally ruled. Exclusively the social tripartite and the economic agreement signed in 2011 were significant to this direction of consensus in structural reforms. Social dialogue also wasn't present during the composition of the Labor Law Reform (2012), which was approved without the consultation or negotiation with the social partners. However, previous experiences and studies have shown that participation of social actors in the decision making process would contribute to higher commitment to the decisions taken (Richardson et al. 2010).

The newly promoted labor market strategies for mitigating the effects of the financial crisis and creating employment are characterized as (Molina and Miguelez 2013): (a) enhanced unilateral regulatory capacity of the employer; (b) wage moderation by strengthening collective bargaining capacities at organizational level and widening the scope of negotiation (e.g. aiming at a better link between real wages and productivity), and (c) a dynamic of balance between the demands received by the organization and the provision of personnel, through measures of internal and functional flexibility. These radical measures involve a scenario of higher internal flexibility but at the same time a higher vulnerability of the worker, as these flexibility criteria are not negotiated between management and employees.

The balance of the achievements reached through social dialogue in times of crisis doesn't look encouraging. The structural reforms of the labor market together with the austerity measures imposed by supranational authorities have weakened the participation of social agents and social dialogue. The threat on social cohesion has been increased by the progressive deterioration of the unemployment protection, a move away from universal coverage, and the social cuts that mainly affect the health and education sectors (Unceta et al. 2014). Furthermore, the expected positive effects on job creation have not yet been reflected in the statistics. Under these circumstances, how are social partners facing social dialogue? Particularly we explore the employers' perspective about the ERs' role. ${ }^{1}$ Before talking about the results of the study, we briefly describe the system of employee representation in Spain, with the goal of better framing the opinions of employers about this role.

Union density in Spain is relatively low at around $16 \%$; however, the overall level of coverage is high at around $70 \%$ of the total workforce. Workplace representation in Spain is articulated through a double system of representation. One side is the so-called unitary representation. These representatives are elected by all

\footnotetext{
${ }^{1}$ The ERs' perspectives have been analyzed in a previous publication: Munduate et al. (2012). Ten steps for empowering employee representatives in the new European industrial relations. Madrid: McGraw Hill.
} 
workers inside the organization and represent the complete workforce. And on the other side you have the union representatives (shop stewards), who are elected only by unionized workers and represent the union in the organization. Both types are members of the works council and both are paid by the employer for their work as representatives. Usually, social elections in Spain take place every 4 years. There are two dominant union confederations in Spain, Comisiones Obreras (CCOO) and the Unión General de Trabajadores (UGT), although there are other important groupings at regional level and in the public sector.

According to the collective bargaining system, negotiations take place at national, sectorial and company level. An annual national agreement provides the framework for lower-level bargaining. As a result from decentralization, currently agreements at organizational level are able to set terms on wages, hours, grading and other issues, such as work-life balance, irrespective of the industry-level agreements. In addition, when a company faces particular financial difficulties, it is able to suspend many of the agreed terms and conditions. The ERs should be consulted on these proposals but if they do not agree the issue goes to arbitration for a decision (Fulton 2013).

\subsection{Current Situation of the ERs. What do Employers Say? Conclusions Drawn from the Interviews}

In this section we summarize the most relevant indicators pointed out by the employers in the interviews regarding the profile of the ERs

The section offers an analysis of 10 semi-structured interviews of Spanish HR managers representing medium to large organizations in various sectors of the Spanish economy. The research examined a European investment bank, two large international energy organizations, two leading international food and drinking organizations, a regional construction organization, a national pharmaceutical distribution organization, a national metal sector organization, a regional transport organization and a traditional large public university. The interviews lasted approximately one hour and a variety of topics related to social dialogue and the role of ERs in Spain were discussed. In the case of multinational organizations the interviews were focused on national activities and labor relations.

The employers' main concerns and expectations regarding labor relations' structures and the role of ERs are summarized below. Although they can't be generalized to all sectors, their reasonings about the following issues matched highly.

1. Complex structure of employee representation. Employers think that the structure of union representation is complex and oversized (overestimated) both in the number of hours assigned to union activities and the number of people involved in such representation. They suggest reducing the structure in order to promote a less costly and effective social dialogue. The reason for this complexity in worker representation has a lot do with the regulation made during 
the transition to democracy to counteract the large period of absence of worker representation, as mentioned before. Managers also think that it's important that the ER structure becomes more flexible and specialized in order to have smaller Work Councils, with more experts prepared to make decisions in different fields (e.g. financial, social). As long as the limits are respected, more flexibility in this issue could help both sides, allowing employers to reduce the representation hours in times of high demand and allowing ERs to request more time when it's needed (e.g., during the negotiation of a collective agreement).

2. Need for professionalism. There is a general consensus among managers about the need to professionalize the ERs' role and training on technical competencies. To be professional doesn't mean to be ideological and vice versa, according to the employers. In this way, in order to improve social dialogue, employers aim for professionalized ERs, ERs for whom ideology is not in the center of their actions and decisions, rather competencies and professionalism.

In this regard, some employers distinguish between the profile of Works Council members elected by the employees, and the profile of those union representatives appointed by trade unions. The latter are seen as having a stronger ideological orientation.

3. Trade unions with one voice. Spanish managers also pointed out that currently there is rivalry between trade unions, both during elections and during labor negotiations. Managers state that the members of the different union sections at the Work Council's level do not speak with one voice making social dialogue more difficult.

4. Openness to innovation. Employers generally point out that there is a systematic refusal to any change or innovation by ERs. Respondents suggest that training should be the way to change the initial opposition to innovation and change. Management representatives emphasize the desire to find competent ERs, trained people with whom they can discuss the development and actual situation of the company and also negotiate over the conflicting interests which may arise. Between the respondents there's a widespread belief that what they find is completely the opposite: lack of technical skills, systematic opposition and unawareness of the company dynamics. All of the sectors agree that ERs should be more innovative and adapt to the evolution of the company and sector. The university HR manager proposes that training should be systematized and oriented to the professionalization of ERs.

5. Restoring prestige. It's important to highlight the low prestige of the role of ERs, inside and outside the organization. Although it is accepted that ERs are as engaged and enthusiastic as their peers, they think there are also cases in which the role is occupied by people with a low profile of skills and performance, who do it to protect themselves against management. The Spanish regulations forbid the lay-off of workers in union representation roles. Employers believe that the role of ER is usually detrimental for a worker's career development; therefore the people with professional potential are not interested in carrying out this position efficiently. Managers point out the need to restore the prestige of the role of ERs in order to attract young people with leadership skills and technical 
knowledge. Furthermore, this role allows candidates to learn about the company from the inside and to participate in decision making, which can be an advantage for acquiring competences.

6. Investing in competencies. Concerning the competencies, there is a general agreement that the level is too low. In the interviews and in the surveys, managers expressed that ERs lack the knowledge and competencies necessary for their role and for successful negotiation. However, there's a widespread will across Spanish managers to meet and work with ERs who are prepared, competent and open to flexibility and change.

Additionally, managers perceive a lack of commitment and involvement with the organization's strategy from the ERs' side. The industrial sector is especially focused on the lack of representation of the overall workforce and a majority of ERs working only for their voters. According to the respondents, many ERs are concerned about self-protectionism instead of being more flexible, working on anticipation and prevention of conflicts.

7. Enhancing the antecedents of trust. Spanish managers point out that many ERs lack the characteristics that they consider as antecedents for creating a trusting relationship, such as the ability or control of specific competences; benevolence, or considering that ERs would do good to the organization; and integrity, or that ERs adhere to a set of principles that the managers find acceptable such as reliability, fairness, justice and consistency. Although all sectors agree that both unions and management distrust each other, it is highlighted by managers that transparency, sensibility towards the needs of both sides, mutual respect and the capacity to understand the information of the other party are needed in order to translate this into integrative agreements.

\subsection{Perceptions of Employers on ERs: Conclusions Drawn from the Surveys}

Results are presented based on the survey among 84 Spanish HR managers of different sectors, compared to the score of $530 \mathrm{HR}$ managers from 10 other countries in Europe (Belgium, Denmark, Estonia, France, Germany, Italy, The Netherlands, Poland, Portugal and the UK). T-tests were conducted to analyze differences between Spanish HR and the rest of European HR managers participating in this study. The significant differences between the Spanish and the European mean have been circled in Fig. 11.1.

In Fig. 11.1 we can see a graph with each variable's mean comparison between Europe and Spain. Spain shows significant differences with Europe in 10 variables, reinforcing the uniqueness of the Spanish industrial relations context.

The level of trust between managers and ERs is significantly lower in Spain $(\mathrm{M}=2.99)$ than in Europe $(\mathrm{M}=3.31)$. This is also the case for ability of ERs ( $M=2.90$ in Spain and $M=3.14$ in Europe), benevolence of ERs ( $M=2.99$ in Spain and $\mathrm{M}=3.35$ in Europe) and integrity of ERs $(\mathrm{M}=3.22$ in Spain and $\mathrm{M}=3.47$ in 

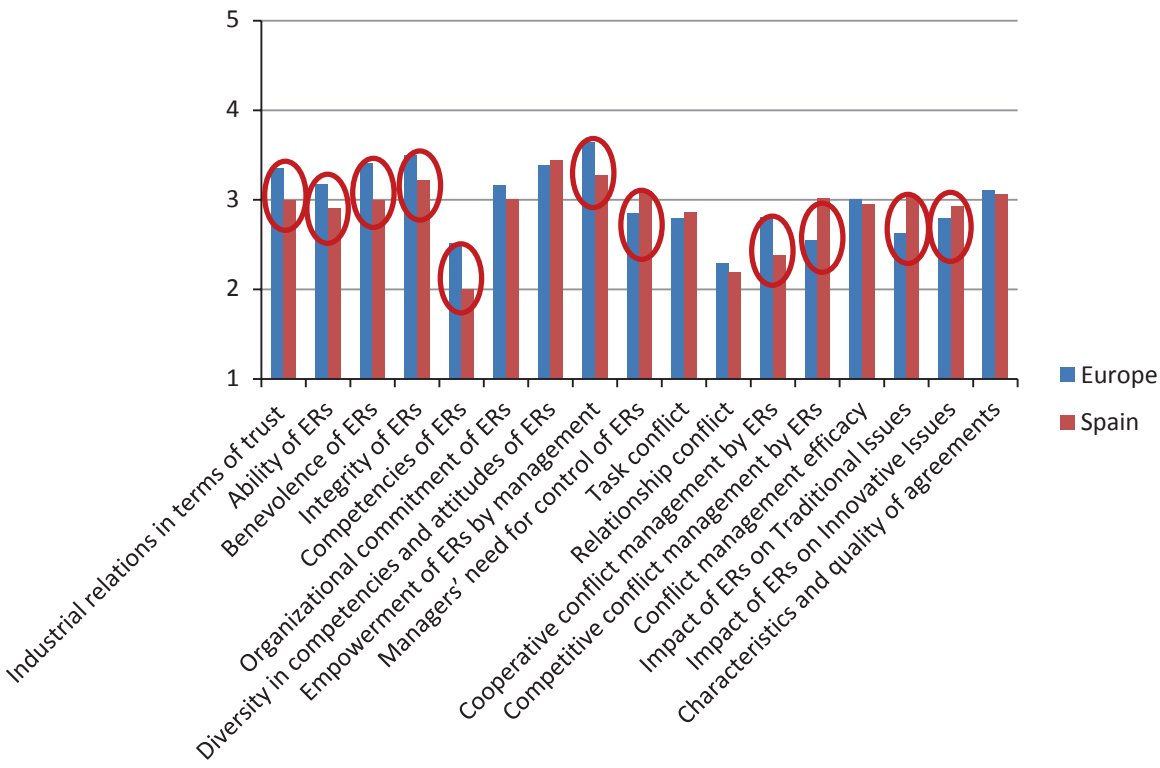

Fig. 11.1 Mean scores of main variables for Spanish and European HR managers

Europe). The first variable is defined by the views HR managers have of the trusting relationship between them and ERs. The following three account for the levels of trustworthiness of ERs as perceived by HR management, that is to say, to what extent do mangers perceive ERs as having the right level of abilities, benevolence and integrity to be able to trust in them. Also for these three antecedents of trust, the mean in Spain is significantly lower than the European mean. These findings suggest that there's a general lack of trust between ERs and management.

The results suggest that HR managers' perception of ERs' competencies is lower in Spain $(M=1.99)$ than in Europe $(M=2.47)$. Competencies in this study refer to human resources management, establishing and maintaining relationships with management, labor law, social skills, business and management, negotiation and conflict management, organizational change and business mergers, stress management and managing complex information (on strategy and change).

Another closely related finding is the empowerment of ERs by management, which was measured through the following item "I support employee representatives in terms of their influence over issues that are important to the organization". Spain scores below $(M=3.27)$ the European average $(M=3.61)$. This finding suggests that the European managers empower ERs more than in Spain, to influence in the organizational decisions.

Moreover, in Spain managers need for control $(\mathrm{M}=3.09)$ scores above the European average $(\mathrm{M}=2.86)$. This also indicates a desire to keep the activities of ERs limited and controlled. 
In terms of conflict management strategies, Spanish HR managers perceive that ERs use a clearly competitive approach in contrast to a cooperative one. Cooperative conflict management by ERs scores lower $(\mathrm{M}=2.38)$ than the European average $(\mathrm{M}=2.76)$. Accordingly, competitive conflict management by ERs $(\mathrm{M}=3.02)$ exceeds the European mean $(\mathrm{M}=2.59)$.

However, the impact by ERs on traditional issues such as working hours or pay appears to be higher in Spain $(M=3.04)$ than in Europe $(M=2.65)$. This finding is probably more related to the normative and centralized collective bargaining system than to an actual cooperative social dialogue, so it should be interpreted with caution.

\subsection{Suggestions Given by Employers to Improve Social Dialogue in Spain}

Both the qualitative and quantitative results of this study clearly point out that Spanish managers perceive a great need for improvements in different aspects of the labor relations' model and particularly in the competencies and attitudes of ERs in Spain.

The main problems expressed by the managers in the interviews are in accordance to the outcomes of the survey, explained in Sect. 11.3. There's a widespread belief that the current model of labor relations is rigid and stuck on needs of the past, and progress is needed in order to adapt to the current needs. Managers consider that the number of ERs and the hours they spend on union activities is too high. Also, they believe that there are ERs who are not committed to the organization but to the union, meaning that they are focusing more on the union ideology than on finding the best solution for the organization (not always incompatible with the best solution for the workers). They propose therefore, to change the election system so ERs will truly represent the interests of all employees in the organization, not only of the unions.

At the same time, managers perceive a lack of competencies and knowledge in ERs. Managers believe that the current situation of stiffness, ideological orientation and lack of competencies, leads to an inflexible position on the ERs' side and a systematic refusal to any innovation. Therefore, the promotion of training in soft and hard skills is needed to rely on more competent ERs who have higher and more productive influence on the decision making process.

Furthermore, managers think they show a competitive conflict management behavior based on the class struggle tradition of Spanish unions. Another reason related to the competitive approach is the low trust between the parties. In this sense, it appears as if the low information sharing and low participation in the decision-making process - together with the low trust between parties - place ERs in a weaker position at the table, leading ERs to use a more competitive rather than a cooperative pattern in conflicts.

Spanish managers point out some suggestions to improve Social Dialogue that are summarized below. 
1. Concerning the ERs' structure there is agreement between managers that it's complex and over dimensioned. Both the number of ERs and the hours they spend working on activities for the union are believed to be too high. In addition, Spanish managers propose to change the current ER election system, especially of the shop stewards - who are elected by union members - which in their view promotes a system in which ERs only defend the interests of the union members. Instead, they propose a system that can attract well prepared, competent people; and also young people with potential, as has been discussed in Sect. 11.3.

2. As seen in the interviews, Spanish managers would like to avoid the rivalry between trade unions. Employers emphasize the importance of negotiating with a strong voice and they therefore believe that the main trade unions (UGT and $\mathrm{CCOO}$ ) should be joined into one because they are on the same side of the table.

3. As clearly shown by the interviews and the surveys, managers believe that ERs should improve their knowledge and competencies for carrying out their role, consequentially improving social dialogue at organizational level. Spanish managers show great motivation for working with competent ERs. They propose to improve the selection process for ERs, together with training in subjects such as business management, economy and communication skills. Employers point out that it's important to make the role attractive to competent people, and especially orient it towards those employees who could have a more flexible attitude to confront the difficulties that may arise.

4. Develop a more open attitude of ERs. Spanish employers believe training in the competences mentioned above also influences the openness to ideas and opportunities, and could therefore help ERs to take into account the interests of the organization and be more flexible during negotiations. Managers believe Spanish ERs are rigid and have an attitude of "never giving in" and this cannot lead to quality agreements. Therefore, training in subjects like business management, finance and negotiation skills can give ERs more tools to work with; this is, to look for integrative solutions for the differences that arise in social dialogue.

5. Improving the industrial relations climate is perceived by employers as an urgent matter, especially in the current strong crisis situation. As they suggest, apart from the historical tradition of competitive industrial relations in Spain, the increase in unemployment, general strikes and job insecurity due to restructuration processes and downsizings together with the austerity policies imposed by supranational authorities are causing organizational conflicts and a tense climate for industrial relations. This shapes one of the worst climates in Europe, following the surveys of the current study. Therefore, managers propose to empower ERs and consequentially improve their role and promote their career development. The starting point of this career is attracting the best people to carry out the role, providing them with training in the competencies indicated above and promoting a trusty culture that we address below.

6. Spanish management systematically highlights the importance of promoting a trusting culture. In order to do so, a suggestion given by most employers is to influence the policies developed by management as well as those developed by 
ERs. They point out the need to be transparent and to promote open communication, together with sensitivity towards employees. Managers refer once again to the need for ERs training to be able to communicate more effectively about different and complex topics related to organizational dynamics and therefore improve trust between the parties. This implication of ERs in organizational issues, together with transparency on the management's side, could promote the culture of trust that Spanish managers so often refer to.

7. Managers state that both parties - managers and employees - should participate in the decision making process and in the organization's strategy. They believe that this is only possible with competent managers and ERs. Furthermore, they express that this participation must involve a commitment between the parties, improving social dialogue in itself in Spain.

8. Managers expressed that the conflict management strategies used by Spanish ERs need to move away from competition. Managers state that training in integrative strategies is crucial, alongside strengthening the "we're in this together" attitude on both sides.

9. Regarding the new framework provided by the Spanish labor market reform, collective bargaining is considered by managers as a potential instrument to gain flexibility and to improve joint reflection. Altogether, managers propose collective bargaining as a very active instrument, which would adapt to the changes in the context and would always have a sense of reality. Moreover, this decentralized model of collective bargaining would serve as a preventive tool, making it possible to arrive to early solutions and therefore preventing possible conflictive and dysfunctional situations.

10. Finally, Spanish managers have indicated that this model of collective bargaining could be of great help for smaller companies, which sometimes struggle in the negotiations for collective agreements. Managers proposes a model of collective bargaining that would lay out the basic lines for negotiation and prevention of problems in the main sectors, but at the same time would leave room for flexibility in its application.

\subsection{Discussion on Expectations of Spanish Employers on ERs' Roles, Attitudes and Competences}

This study has analyzed the role and structures of ERs in Spain and has provided some measures for constructing a more competitive role for confronting the new requirements of an economy in times of austerity, from the perspective of HR managers. These measures must be considered in the context of industrial relations and in line with the global measures which are been proposed with Spain's recovery in focus (Pérez García 2013; Ramos and Peiró 2014). They are related to: (a) the need to prepare and train human resources as a whole: improvement of the training of employers and employees, business training for graduates, continuous educa- 
tion, active employment policies to qualify unemployed people; (b) to use human resources more effectively for increasing productivity, which is being achieved by eliminating the less productive jobs, at the same time as new jobs are created; (c) to advance in the intermediation tasks to promote employment and part-time work; and (d) facilitating entrepreneurship, reducing bureaucratic obstacles and supporting it with expert knowledge. The proposals for reconstructing the role of ERs in Spain are embedded in this context of economic recovery and social innovation.

Two of the most relevant findings of the current research refer to the experiences of the managers in relation to the significantly different role of the ERs in Spain in comparison to those in other European countries, and to the managers' common expectations about the changes they want to see in this role.

The key differential issue of the Spanish profile has to do with the context of crisis and economic recession that the country is currently going through. The cooperation climate is put under high stress and there's an additional large opposition in social relationships. ERs and managers perceive and behave as two opposed groups, subject to high levels of conflict. As Deutsch indicates (2006), in managing conflict competitively, people convey that they want to use the conflict to promote their goals at the expenses of the other. They want to "win" and have the other "lose". In addition to the current crisis, another factor that could maximize confrontation between the parties is the labor relations tradition in Spain. If we interpret this in terms of conflict cultures or socially shared norms for how conflict should be managed (Gelfand et al. 2012), the relations tradition in Spain would be close to what has been called a dominating conflict culture, characterized by conflict management norms that encourage active confrontation in order to publicly win conflicts (Gelfand et al. 2008). Underlying this conflict culture is the assumption that individuals have the agency to openly deal with conflict and that disagreeable or competitive behaviors are appropriate and normative. Normative behaviors for handling conflicts may include direct confrontations and heated arguments in which individuals are reluctant to give in, yelling and shouting matches, or threats and warnings (Gelfand et al. 2012). Dominating, competition, and active confrontation have been associated with reduced viability at interpersonal and group relationship level (Gelfand et al. 2008). Managers' reports on industrial relations and conflict management in Spain don't indicate the best scenario. However, there's a shared interest in improving this among Spanish employers.

Another differential aspect of the Spanish profile refers to the combination of both a perceived lack of competencies of ERs regarding the dynamics of the organization, and a lack of trust in them from managers. In the same direction, research has shown that trustors are concerned about vulnerability associated with the potential loss from trusting. Ergo, trusting involves a great risk because it is done with expectations of future behaviors. Therefore, in order to trust the other party and assume the risk, people need to perceive certain characteristics in them (Özer et al. 2011). In this sense, to the extent that the managers can engender positive perceptions in the ERs - that is, ERs being able, benevolent and of integrity - a trusting relationship is more likely to take place (Fulmer and Gelfand 2012). Developing a trusting re- 
lationship is essential to be able to understand organizational dynamics as well as promoting organizational productivity and team performance (Hempel et al. 2009).

Although the characteristics of the ERs profile as described by the employers don't encourage facing the urgency of the development of constructive dialogue in Spain, the second finding however does give hope and shows a change of trend in the relationships between social partners. The relevance of this change means the discovery of the Philosophers'stone for labor relations, and it's related to the expectations expressed by managers when referring to the role and structure of ERs. In this sense, employers show that the model of labor relations - which emerged in the industrial era at the beginning of the twentieth century - that has prevailed till today is not viable in the current era of knowledge of the twenty-first century. They observe that we are in a moment of historical transition of the model, from one based on distrust, control and systematic antagonism-more in line with tyranny of the Taylorist principles of production and management - to a model of social dialogue, with flexibility, based on mutual trust and confidence among the parties involvedmore in line with the alchemy of flexibility and trust (Stone and Arthurs 2013). As indicated by the European Commission (2010), the problem-solving potential of social dialogue will be crucial, in the long term, for socially fair and well managed transition within the EU zone. Implementing this model of social dialogue ties up with the expressed will by Spanish managers to work with competent counterparts at the negotiation table, partners who have a strategic vision of the dynamics of the organization and with whom they can work vis-à-vis through transparency, in a constructive and innovative dialogue about issues of common interest relating to economic and social policy. They point out that empowering ERs so that they can achieve these competencies, together with the professionalization of their role, are further challenges for both ERs and employers, which will eventually allow ERs to have a sustainable and worthy career, with good social prestige. The transition from the tyranny of Taylorism to the alchemy of trust and flexibility requires new forms of participation, new structures of representation, and the strengthening of competences of all social partners.

Open Access This chapter is distributed under the terms of the Creative Commons Attribution Noncommercial License, which permits any noncommercial use, distribution, and reproduction in any medium, provided the original author(s) and source are credited.

\section{References}

Aiginger, K. (2013). A Southern Europe strategy based on vision and industrial policy. Ekonomiaz, 82, (1er cuatrimestre), 127-168.

Banyuls, J., Miguelez, F., Recio, A., Cano, E., \& Lorente, R. (2009). The transformation of the employment system in Spain: Towards a Mediterranean neoliberalism? In G. Bosch, S. Lehndorff, \& J. Rubery (Eds.), European employment models in flux: A comparison of institutional change in nine European countries. New York: Palgrave Macmillan. ISBN: 0230223559. 
Benito, R. (Eds.) (2012). Un sindicalismo para el futuro. Reflexiones sobre el trabajo y el cambio social [A trade unionism for the future. Reflections about work and social change]. Madrid: Fundación 1 de Mayo, Comisiones Obreras, CCOO.

Carballo-Cruz, F. (2011). Causes and consequences of the Spanish economic crisis: Why the recovery is taken so long? Panoeconomicus, 3, 309-328.

Deutsch, M. (2006). Cooperation and competition. In: Deutsch, M., Coleman, P. T. \& Marcus, E. (Eds.), The Handbook of Conflict Resolution: Theory and Practice (pp. 23-42). San Francisco: Jossey-Bass.

Duran, J. \& Isusi, I. (2010). Working poor in Europe: Spain. European Working Conditions Observatory. www.wurofound.europa.eu.

Elgoibar, P. (2013). Worker representatives' conflict behavior in Europe. With a focus on Spain, University of Leuven and University of Seville. PhD dissertation.

Elgoibar, P., Munduate, L., Medina, F. J., \& Euwema, M. C. (2012). Why are industrial relations in Spain competitive? Trust in management, union support and conflict behavior in worker representatives. Revista Internacional de Organizaciones, 9, 145-168.

European Commission. (2010). Industrial relations in Europe 2010. Brussels: Directorate-General for Employment, Social Affairs and Inclusion.

Eurostat. (2013). Employment and social policies indicators. http://epp.eurostat.ec.europa.eu/portal/page/portal/employment_social_policy_equality/introduction.

Fishman, R. (2012). Anomalies of Spain's economy and economic policy making. Contributions to political economy, 31(1), 67-76.

Fulmer, C. A., \& Gelfand, M. J. (2012). At what level (and in whom) we trust: Trust across multiple organizational levels. Journal of Management, 38(4), 1167-1230.

Fulton, L. (2013). Worker representation in Europe. Labour Research Department and ETUI.

Gelfand, M. J., Leslie, L. M., \& Keller, K. (2008). On the etiology of organizational conflict cultures. Research in Organizational Behavior, 28, 137-166.

Gelfand, M. J., Leslie, L. M., Keller, K., \& De Dreu, C. De Dreu, C. K. (2012). Conflict cultures in organizations: How leaders shape conflict cultures and their organizational-level consequences. Journal of Applied Psychology, 97(6), 1131-1147.

Hempel, S., Zhang, Z., \& Tjosvold, D. (2009). Conflict management between and within teams for trusting relationships and productivity in China. Journal of Organizational Behavior, 30, 41-65.

Hyman, R. (2005). Whose (social) partnership? In M. Stuart \& M. Martinez Lucio (Eds.), Partnership and modernization in employment relations (pp. 251-265). New York: Routledge.

Laborda, A. (2010). La economía española en la encrucijada: Diagnóstico y estrategias de salida. [Spanish economy in a dilemma: Diagnostics and solutions]. Cuadernos de Información Económica, 214, 65-72.

Martínez-Lucio, M. (2008). Todavía organizaciones del descontento. Los retos de las estrategias de renovación sindical en España [Still organizations of the discontent? Challenges for union renewal strategies in Spain]. Arxius de Ciencies Socials, 18, 119-133.

Martínez-Lucio, M., \& Weston, S. (2007). Preparing the ground for a Social Europe? European works councils and European Regulatory Identity. In M. Whittall, H. Knudsen, \& F. Huijgen (Eds.), Towards a European labor identity. London: Routledge.

Mas, M., Milana, C., \& Serrano, L. (2012). Spain and Italy: Catching up and falling behind. Two different tales of productivity slowdown. In M. Mas \& R. Stehrer (Eds.), Industrial productivity in Europe: Growth and crisis (pp. 161-191). Cheltenham: Edward Elgar.

Miguélez, F., \& Prieto, C. (2009). Transformations of employment, flexibility and industrial relations in Europe. Política y Sociedad, 46(1-2), 275-287.

Molina, O. \& Miguelez, F. (2013). From negotiation to imposition: Social dialogue in austerity times in Spain (Working paper, n. 51). Geneva: International Labor Officce (ILO).

Munduate, L. (1993). La aproximación psicosocial al estudio del conflicto y la negociación laboral en España. Una revisión. [A psychosocial approach to conflict and labor negotiation in Spain. A review.] Psicothema, 5, 261-275. 
Munduate, L., Ganaza, J., Alcaide, M., \& Peiró, J. M. (1994). Conflict management in Spain. In R. A. Rahim, \& A. Blum A. (Eds.), Global perspectives on organizational conflict (pp. 103-134). New York: Praeger.

Munduate, L., Euwema, M., \& Elgoibar, P. (2012). Ten steps for empowering employee representatives in the new European industrial relations. Madrid: McGraw Hill.

Özer, Ö., Zhen, Y., \& Chen, K-Y. (2011). Trust in forecast information sharing. Management Science, 57, 1111-1137.

Pérez García, F. (2011). Crecimiento y competitividad. Trayectoria y perspectivas de la economía española. Informe Fundación BBV-IVIE, 2011. Bilbao: Fundación BBV.

Pérez García, F. (2012). Crecimiento y Competitividad. Motores y frenos de la economía española. Informe Fundación BBV-IVIE, 2011. Bilbao: Fundación BBV.

Pérez García, F. (2013). Crecimiento y competitividad. Los retos de la recuperación. Informe Fundación BBV-IVIE, 2011. Bilbao: Fundación BBV.

Ramos, J., \& Peiró, J. M. (2014). La psicología del trabajo y de las organizaciones en tiempos de crisis económica. Papeles del Psicólogo, 35(1), 1-4.

Richardson, M., Danford, A., Stewart, P., \& Pulignano, V. (2010). Employee participation and involvement: Experiences of aerospace and automobile workers in the UK and Italy. European Journal of Industrial Relations, 16(1), 21-37.

Rigby, M., \& Lawlor, T. (1994). Spanish trade unions 1986-1993. Industrial Relations Journal, 25(4), 258-271.

Rocha, S. R. (2010). Shop stewards as coordinators of employee-driven innovation (EDI): Implications for trade unions. Transfer: European Review of Labor and Research, 16(2), 185-196.

Ruiz-Galvez Juzgado, M. E. (2012). Políticas de ajuste estructural y su impacto en el mercado de trabajo español (1994-2010) [Structural adjustment policies and their impact on the Spanish labor market (1994-2010)]. Contribuciones a la Economia, Octubre 2012 (online journal).

Sánchez-Cuenca, I., \& Aguilar, P. (2009). Terrorist violence and popular mobilization. The case of the Spanish transition to democracy. Politics \& Society, 37(3), 428-453.

Sanz de Miguel, P. (2013). Spain: The impact of the crisis on industrial relations. Eurofound. Brussels: European industrial relations observatory.

Statistic National Institute. (2013). Encuenta de poblacion activa [Labor Force Survey].

Stone, K. V. W., \& Arthurs, W. (2013). Rethinking Workplace Regulation: Beyond the Standard Contract of Employment. New York: Russel Sage Foundation.

Unceta, K., Garmendia, J., Elgoibar, P., \& Heras, I. (23 February 2014). Por una economia al servicio de las personas [For an economy in the service of people. El Pais Newspaper. 